\title{
Innovative Off-Board EV Home Charging Station as a Smart Home Enabler: Present and Proposed Perspectives
}

\author{
Vítor Monteiro $^{1}$, Tiago J. C. Sousa ${ }^{1}$, José A. Afonso ${ }^{2}$, João L. Afonso ${ }^{1}$ \\ ${ }^{1}$ ALGORITMI Research Centre - University of Minho, Guimarães - Portugal \\ ${ }^{2}$ CMEMS-UMinho - University of Minho, Guimarães - Portugal \\ ${ }^{1}\left\{\right.$ vmonteiro | tsousa $\mid$ jla\}@dei.uminho.pt ${ }^{2}$ jose.afonso@dei.uminho.pt
}

\begin{abstract}
This paper presents an innovative off-board electric vehicle home charging station (EV-HCS) operating as a smart home (SH) enabler. The present status and the proposed perspectives in terms of operation modes are comprehensively addressed along the paper showing the contextualization of the addressed research topic. Comparing with the existing solution, the main motivations and advantages of the off-board EV-HCS are: (a) Off-board dc EV charger, faster than a classical on-board EV charger; (b) Flexible operating power value, aiming an optimized power management in the home; (c) Operation as an active conditioner for the home or the grid, with or without an EV plugged-in, which represents an attractive functionality for enhancing the operation of SHs and smart grids; (d) Bidirectional operation with an EV. The methods used to describe these advantages are validated using computer simulations. The control algorithm is succinctly described, demonstrating its adaptability to the power electronics topology presented for the EV-HCS hardware. The obtained results demonstrate that the proposed EV-HCS presents attractive functionalities for enhancing the $\mathrm{EV}$ integration into SHs and smart grids.
\end{abstract}

Keywords-Electric Vehicle, Flexible Power Control, Power Quality, Smart Home, Smart Grid, Home Charging Station.

\section{INTRODUCTION}

Along the last years, the commercially available electric vehicles (EVs) were equipped with on-board battery chargers that are only able to accomplish basic charging from the grid [1], [2]. This operation, classified as grid-to-vehicle $(\mathrm{G} 2 \mathrm{~V})$, is controlled only by the on-board EV charger, without considering the grid constraints. As a consequence, the massive and uncontrolled introduction of EVs may bring several critical drawbacks in the operation of the grid, both in terms of efficiency and power quality [3-7], as exemplified in [8], which presents a power quality analysis for the smart grid (SG) in view of the inclusion of EVs.

Given the trend of wide dissemination of electric mobility around the world in the near future, besides the G2V operation mode, new perceptions for the EV operation are emerging, which place the EV as an asset to the grid [9]. The perspectives of contribution of the EV operation for microgrids and SGs, in terms of flexibility of charging, are presented, respectively, in [10] and [11]. Taking into account that the EV is generally parked during long times, it can act as an energy storage system. Therefore, the option to use the stored energy in the EV battery arises as a relevant influence factor to support the grid in terms of stability. This operation, classified as vehicle-to-grid (V2G), is one of the most promising factors for the EV integration toward the development of a SG [12-14]. Experimental validations of these applications are presented in [15] and [16], and the evolution of the G2V and V2G interactions with the grid is presented in [17]. In a SG perspective, it is conceivable to establish an energy management approach considering the EV operation as an energy storage system through the G2V and V2G modes [18]. As an example, a power management strategy enhancing the EV operation in microgrids is presented in [19]. This bidirectional operation is more significant due to the regular intermittence of the energy produced from renewable energy sources, where the EV can symbolize an interesting option to exchange energy with the grid. In this context, a cooperative $\mathrm{EV}$ charging with renewables targeting to diminish greenhouse gases emissions is presented in [20], a demand-side management approach using renewables and the EV in G2V and V2G modes is presented in [21], and the EV utilization with renewables towards the reduction of costs and emissions is presented in [22].

Associating all of its benefits for diverse circumstances of operation, the EV appears as a key element in SGs, where the home charging will also contribute to the dissemination of SHs. In fact, SHs represent a booster effect for the SGs operation [23]. A set of technologies, methodologies, approaches, and foresights to assimilate the EV into a $\mathrm{SH}$ is presented in [24], and the customer perspective of an optimized EV charging process is presented in [25]. As a consequence, new challenges in terms of charging infrastructures involving $\mathrm{SHs}$ are emerging, where, besides the charging from the classical on-board EV charger, the EV can be charged from off-board chargers with higher power ratings [26]. Off-board charging infrastructures are appearing with different power ratings (from few $\mathrm{kW}$ to hundreds of $\mathrm{kW}$ ) as a contribution to accomplish the $\mathrm{EV}$ owner requirements, mainly to reduce the EV range anxiety [27].

In the scope of this paper, a new concept for the EV home charging is presented, where an innovative off-board EV home charging station (EV-HCS) is proposed as a $\mathrm{SH}$ enabler. Accordingly, besides the operation in G2V and V2G modes, the main contributions of this paper are described as follows: (a) EV-HCS prepared to charge the EV through a dc interface directly to the EV battery, performing the charging as fast as possible, i.e., faster than an on-board charger $(>3.5 \mathrm{~kW})$, but 


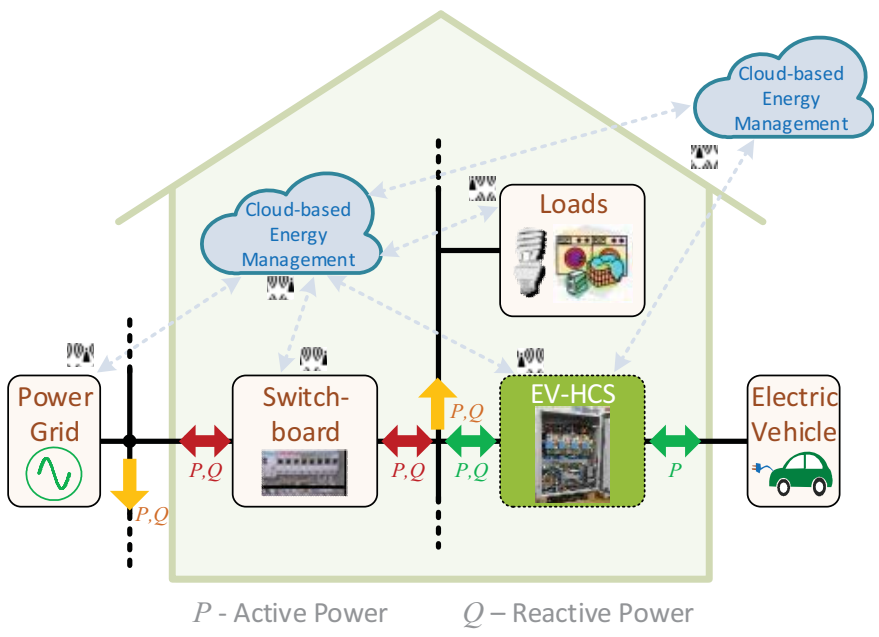

Fig. 1. EV-HCS framed in a SH scenario.

slower than a public off-board charger $(<50 \mathrm{~kW})$; (b) As a contribution for $\mathrm{SHs}$, the EV-HCS regulates its operational power as a meaning of the operating power of the other electrical appliances, i.e., establishing a power management strategy for all the plugged-in electrical appliances at the home; (c) Off-board single-phase EV-HCS able to operate as an active conditioner, permitting to compensate power quality problems caused by the electrical appliances and/or to provide power quality functionalities to the SG; (d) Power quality compensation at home level, performed with or without an EV plugged-in, which signifies an attractive functionality for enhancing the operation of SHs and SGs.

The EV-HCS, as well as the proposed different functionalities, represents numerous new contributions when compared with the classical EV supply equipment (EVSE). However, it is also imperative to note that some interesting ideas related to the EV utilization in SHs were already explored. For instance, a flexible EV charging process is offered in [28], however, only for an on-board EV charger and without the option to operate as an active power conditioner. New perspectives of action for an EV charger are presented in [29], including the possibility to compensate power quality issues, however, only for an on-board EV charger, i.e., the new functionalities are only accessible when the EV is plugged-in. A simultaneous operation of an EV charger as an active filter and as a charger is proposed in [30], however, the application is limited to an on-board EV charger. An EV battery charger permitting to produce reactive power to the grid is proposed in [31], however, it is an on-board charger, where its process in $\mathrm{SHs}$ is limited to the period when the EV is plugged-in there. Analyzing all of these influences from the SH point of view, these functionalities are only viable when the EV is plugged-in, demonstrating a relevant disadvantage. This is even more problematic seeing the fact that the EV tends to be arbitrarily connected to the grid.

Fig. 1 shows the EV-HCS, framed in a SH scenario, where the active and reactive power at the different points inside the $\mathrm{SH}$ are identified. The EV-HCS, as well as the electrical appliances, are connected to the grid through the switchboard, where is measured the current used in the control algorithm. The reactive power in the ac side of the $\mathrm{SH}$ means that the
EV-HCS can provide capacitive or inductive reactive power for the $\mathrm{SG}$, since the reactive power of the electrical appliances are compensated internally in the $\mathrm{SH}$ by the EV-HCS. A bidirectional operation with the EV battery is established by the EV-HCS directly through the dc EV interface. As shown in Fig. 1, an internal cloud-based energy management is presented for the $\mathrm{SH}$, establishing bidirectional communication with the EV-HCS and contributing to the definition of the functioning modes. Moreover, in order to support the grid, bidirectional communication is also recognized with an external cloud-based energy management.

The paper is structured according as follows: section II describes the EV-HCS and its interaction with the SH; section III presents the control algorithm in the context of a SH; section IV presents a computational validation of the proposed system; section $\mathrm{V}$ finalizes the paper with the main conclusions.

\section{EV-HCS PROPOSED STRUCTURE}

The hardware structure for the EV-HCS is presented in Fig. 2, where a single-phase three-level ac-dc converter interfaces the grid and a three-level dc-dc converter interfaces the EV for a dc battery charging. Both the ac-dc and dc-dc converters are controlled by a current feedback, and both converters are connected through a dc-link. The above-mentioned topologies of single-phase ac-dc and dc-dc converters are quite relevant in an industrial electronics perspective; however, other topologies, as well as control strategies, can be adopted with the proposed functionalities.

The digital control is implemented based on the acquired variables from the grid-side (ac variables) and from the EV side (dc variables), allowing to control the EV-HCS as a unified power converter, with or without an EV plugged-in. Besides, it also contemplates bidirectional communication with the internal or external cloud-based energy management (cf. Fig. 1) with the objective to define set-points of operation (e.g., operating schedules and modes of operation) for the $\mathrm{SH}$ or for the SG operation.

The structure of the control algorithm for the EV-HCS is presented in Fig. 3, where the distinct modes are identified. As it can be seen, several different scenarios are available, considering the possibility of operation as EV charging $(\mathrm{G} 2 \mathrm{~V}$ mode), EV discharging (V2G mode), active conditioning for the $\mathrm{SH}$ (home conditioner), or active conditioning for the SG (grid conditioner). Moreover, the association of some of these modes is also possible. For example, at the same time, the EV-HCS can operate as EV battery charger (G2V mode) and as active conditioner (compensating harmonics in the $\mathrm{SH}$ and producing reactive power as a influence to improve the power quality in the SG).

\section{EV-HCS DigITAL CONTROL IMPLEMENTATION}

The control is established according to the presence of an $\mathrm{EV}$ (the EV can be plugged-in or not) and the requirements of power quality for the SH or for the SG. When the EV-HCS is compensating power quality problems without the EV plugged-in, the SH operates permanently with sinusoidal current, independently of the power quality problems associated to the voltage. In this case, only the necessary active power for the electrical appliances is provided by the grid, 


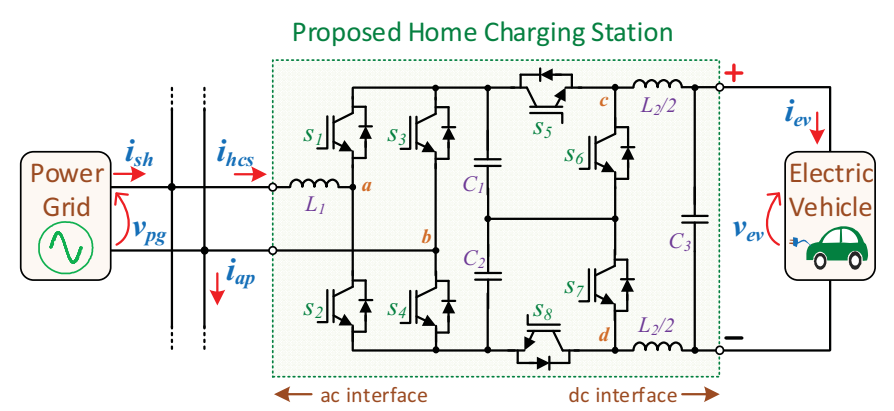

Fig. 2. Hardware structure for the EV-HCS.

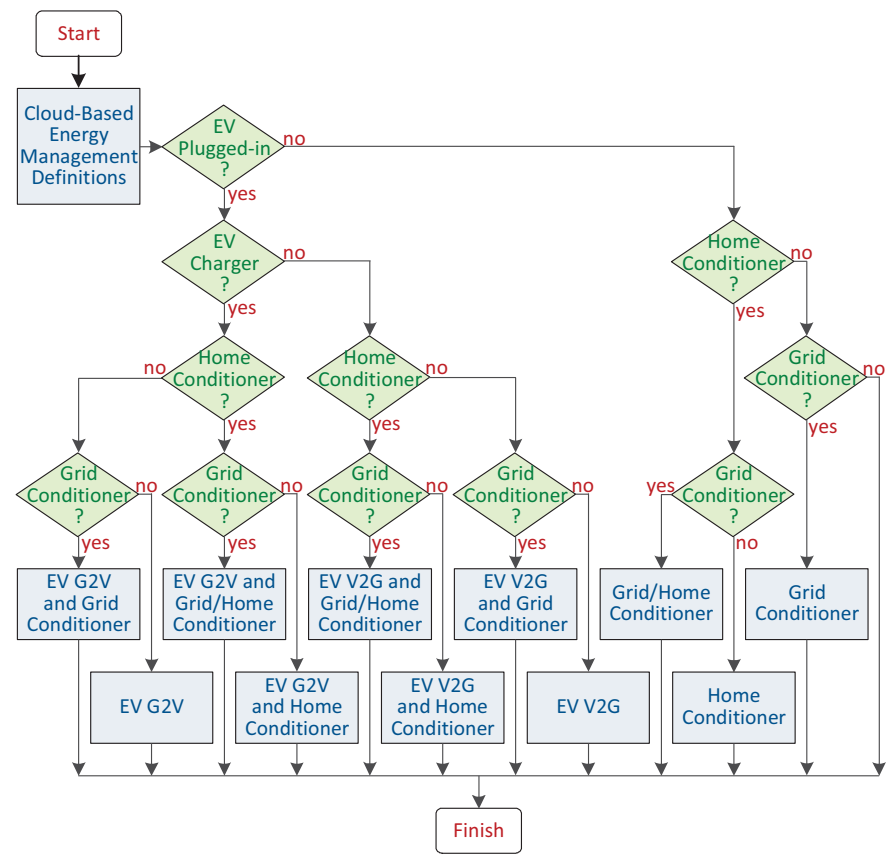

Fig. 3. Structure of the control algorithm for the EV-HCS.

since the EV-HCS provides the reactive power and compensates the current harmonics of the electrical appliances. Therefore, from the grid point of view, the current in the $\mathrm{SH}$ is established as:

$$
I_{S H}=\frac{P_{S H}}{V_{P G}},
$$

where $I_{S H}$ denotes the rms value of the $\mathrm{SH}$ current, $P_{S H}$ the active power in the $\mathrm{SH}$, and $V_{P G}$ the rms value of the grid voltage. From (1), the value of the instantaneous power in the grid-side is determined as:

$$
p_{s h}(t)=i_{s h}(t) v_{p g}(t) .
$$

In the worst case, the EV-HCS should compensate the harmonics and the reactive power consumed by the appliances. Therefore, as the control is digitally implemented, the current value of the EV-HCS is determined as:

$$
i_{h c s}{ }^{*}[n]=\frac{P_{A P}[n]}{\left(V_{P G}[n]\right)^{2}} v_{p g}[n]-i_{a p}[n],
$$

where $i_{a p}$ denotes the instantaneous value of the electrical appliances current and $P_{A P}$ the active power consumed by the appliances, which is equal to the active power of the SH when the EV-HCS is only operating as active conditioner (i.e., without a plugged-in EV). The value of $P_{A P}$ is obtained with a moving average as:

$$
P_{A P}[n]=\frac{1}{M} \sum_{i=0}^{M-1} i_{a p}[i-1] v_{p g}[i-1],
$$

where $M=800$ for a sampling frequency of $40 \mathrm{kHz}$. The rms value of the grid voltage is digitally determined during a grid period as:

$$
V_{P G}[n]=\sqrt{\frac{1}{M} \sum_{i=1}^{M} v_{p g}[i]^{2}} .
$$

Both $P_{A P}$ and $V_{P G}$ are continuously updated during each sampling period $[n, n+1]$ with the obtained samples at $[n]$. Equation (3) defines the ac-side current of the EV-HCS $\left(i_{h c s}\right)$ when the EV is not plugged-in. On the other hand, when an EV is plugged-in, the necessary active power is provided by the grid to the EV-HCS. Therefore, a parcel of power, defined by $i_{e v}$ and $v_{e v}$, is added to (3), resulting in:

$$
i_{h c s}{ }^{*}[n]=\frac{P_{A P}[n]+\left(i_{e v}[n] v_{e v}[n]\right)}{\left(V_{P G}[n]\right)^{2}} v_{p g}[n]-i_{a p}[n] .
$$

When the EV-HCS is used to charge (G2V) or discharge (V2G) the EV battery, to compensate harmonics in the $\mathrm{SH}$ and to produce reactive power for the $\mathrm{SG}$, the current value of the EV-HCS is determined as:

$$
\begin{aligned}
i_{h c s}{ }^{*}[n]=\frac{P_{A P}[n]+\left(i_{e v}[n] v_{e v}[n]\right)}{\left(V_{P G}[n]\right)^{2}} & v_{p g}[n]-i_{a p}[n]+ \\
& +\frac{Q^{*}}{\left(V_{P G}[n]\right)^{2}} v_{p g}[n],
\end{aligned}
$$

where $Q^{*}$ is the reference reactive power established by the SG to be produced by the EV-HCS. This is the main control equation, since all the modes can be defined from it. The value of $i_{h c s} *[n]$ is calculated by the control with the variables acquired in the instant $[n]$, and is maintained during the period $[n, n+1]$. Aiming to get a sinusoidal current $i_{h c s} *$ independently of the grid voltage waveform, a phase-locked loop (PLL) is used in detriment of the real measured value. The value of $i_{h c s}$ * is used as reference for the ac-dc converter in the control strategy, defined by:

$$
i_{h c s}{ }^{*}[n]=i_{h c s}[n]-L_{1}{ }^{-1} T_{s}\left(v_{p g}[n]-v_{a c}[n]\right),
$$

where $i_{h c s}$ is the measured current, $L_{l}$ the inductance value of the coupling passive filter in the ac side, $T_{s}$ the sampling period of the control, and $v_{a c}$ the pulse-width modulation (PWM) voltage produced by the converter in the ac side downstream the coupling passive filter (cf. Fig. 2 the voltage established between the points $a$ and $b$ ). A unipolar PWM is used to select the state of each controlled semiconductor (in this case IGBTs are used) during the EV-HCS operation (i.e., the voltage $v_{a c}$ ). On the other hand, the reference current for the dc-dc converter is defined by the battery management system according to the battery state-of-charge and the current is controlled by:

$$
i_{e v}{ }^{*}[n]=i_{e v}[n]-L_{2}{ }^{-1} T_{s}\left(v_{d c}[n]-v_{e v}[n]\right),
$$


where $i_{e v}$ is the measured current, $L_{2}$ the inductance value of the coupling passive filter in the dc side, and $v_{D C}$ the PWM voltage produced by the converter in the dc side downstream the coupling passive filter (cf. Fig. 2 the voltage among the points $c$ and $d$ ). A PWM is used to choice the state of each IGBT throughout the EV-HCS operation (i.e., the voltage $v_{d c}$ ).

\section{EV-HCS COMPUTATIONAL VALIDATION}

A computational validation was performed using the PSIM software. The established model of the system (EV-HCS and the SH electrical appliances) was implemented contemplating real scenarios of operation, namely in terms of the harmonic content for the electrical appliances current and grid voltage. A Fluke 435 power quality analyzer was used to measure the harmonic content in a real installation and the attained values of voltage and current (amplitude and phase of each harmonic) were used in the developed model.

Fig. 4 shows the active and reactive power in the $\mathrm{SH}\left(P_{S H}\right.$, $\left.Q_{S H}\right)$, in the electrical appliances $\left(P_{A P}, Q_{A P}\right)$, and in the EV-HCS $\left(P_{H C S}, Q_{H C S}, P_{E V}\right)$. This result was obtained to show the EV-HCS operation during the EV charging and discharging, and compensation of the current harmonics and the reactive power. Therefore, the active power in the $\mathrm{SH}$ is composed by the active power consumed by the appliances and the active power necessary for the EV charging. As the current harmonics and the reactive power are compensated by the EV-HCS, the reactive power in the grid-side is null. The reactive power produced by the EV-HCS is represented with a negative value due to the inductive reactive power consumed by the appliances, whereby the EV-HCS must supply capacitive reactive power. As shown in this figure, this result was obtained during 6 distinct stages: (1) The EV-HCS is turned-off, i.e., the active power and the reactive power in the home are established by the active power and the reactive power consumed by the electrical appliances; (2) The EV-HCS is turned-on to compensate the current harmonics and reactive power, i.e., to operate as active power conditioner; (3) The EV-HCS starts the operation as G2V (charging the EV battery) combined with the operation as active conditioner; (4) An electrical appliance is connected to the grid, increasing the active power in the grid-side and forcing the compensation of the EV-HCS, but the charging power of the EV (in the dc side) remains the same; (5) The EV charging is stopped $\left(P_{E V}=0\right)$ with the EV-HCS only operating as active power conditioner; (6) besides the operation as active power conditioner, the EV-HCS starts the operation as V2G (discharging the EV battery to the grid).

Fig. 5 shows the instantaneous measured values of the grid voltage $\left(v_{p g}\right)$, the $\mathrm{SH}$ current $\left(i_{s h}\right)$, the electrical appliances current $\left(i_{a p}\right)$, and the EV-HCS current $\left(i_{h c s}\right)$. As a support to exemplify the benefits of the EV-HCS, this figure shows two distinct cases, namely before and after the operation as active conditioner (i.e., compensating harmonics and reactive power). Before the operation as active conditioner, the instantaneous value of the home current $\left(i_{s h}\right)$ is directly the sum between the electrical appliances current $\left(i_{a p}\right)$ and the EV-HCS current $\left(i_{h c s}\right)$, resulting in a distorted consumed current from the grid, contributing to aggravate power quality problems. On the other hand, after the operation as active conditioner, the EV-HCS

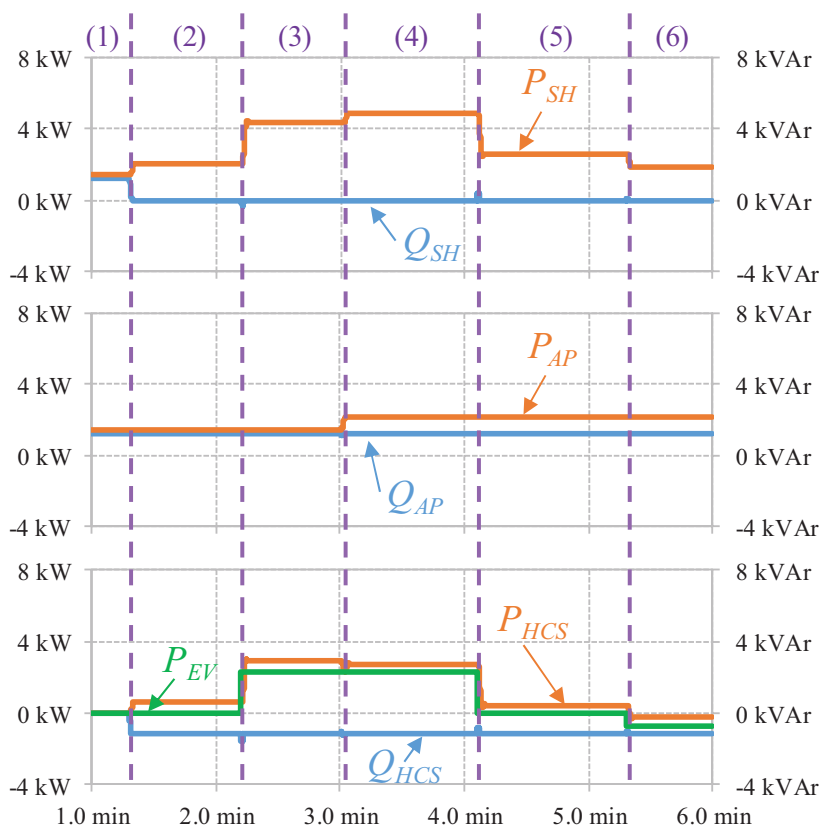

Fig. 4. EV-HCS operation during EV charging and discharging, with compensation of current harmonics and reactive power caused by nonlinear electrical appliances, showing the active power and the reactive power in the: $\mathrm{SH}\left(P_{S H}, Q_{S H}\right)$; Electrical appliances $\left(P_{A P}, Q_{A P}\right)$; and EV-HCS $\left(P_{H C S}, Q_{S C H}\right.$, $\left.P_{E V}\right)$.

current is established to get a sinusoidal current in the ac-grid side of the SH. As it can be seen, the SH current is sinusoidal, meaning that only active power is provided by the grid. In this case, as expected, the appliances current remains, exactly, the same, i.e., the appliances operation are not influence by the $\mathrm{EV}-\mathrm{HCS}$ operation. It is worth to mention that the SH current is sinusoidal independently of the harmonic distortion presented in the grid voltage, which is important to preserve the power quality in the grid side. In a SG perspective, where the use of the EV-HCS is predicable, the harmonic content of the grid voltage will be reduced, since the circulating currents in the distribution lines will be practically sinusoidal. Moreover, since this proposal is not limited to SHs, but can also be applied to other sectors (e.g., service buildings and industries), the achieved results will have a more important positive impact.

Fig. 6 also shows the active and reactive power in the $\mathrm{SH}$ $\left(P_{S H}, Q_{S H}\right)$, in the electrical appliances $\left(P_{A P}, Q_{A P}\right)$, and in the EV-HCS ( $\left.P_{H C S}, Q_{H C S}, P_{E V}\right)$. This result was attained to show the EV-HCS during the EV charging and discharging, and compensating the harmonics and the reactive power due to the nonlinear appliances. This result was also obtained to show EV-HCS regulating its power as a function of the operating power of the other appliances in the SH, i.e., establishing a power management strategy for all the appliances plugged in at the SH. Therefore, due to the flexible working power of the EV-HCS, the active power in the home $\left(P_{S H}\right)$ is maintained constant even changing the active power consumed by the electrical appliances $\left(P_{A P}\right)$.

This flexibility is also a key factor for a massive addition of EVs into the grid, since it allows to establish a set of coordinated EV charging strategies. Fig. 7 shows the active and reactive power in the $\mathrm{SH}\left(P_{S H}, Q_{S H}\right)$, in the electrical appliances 


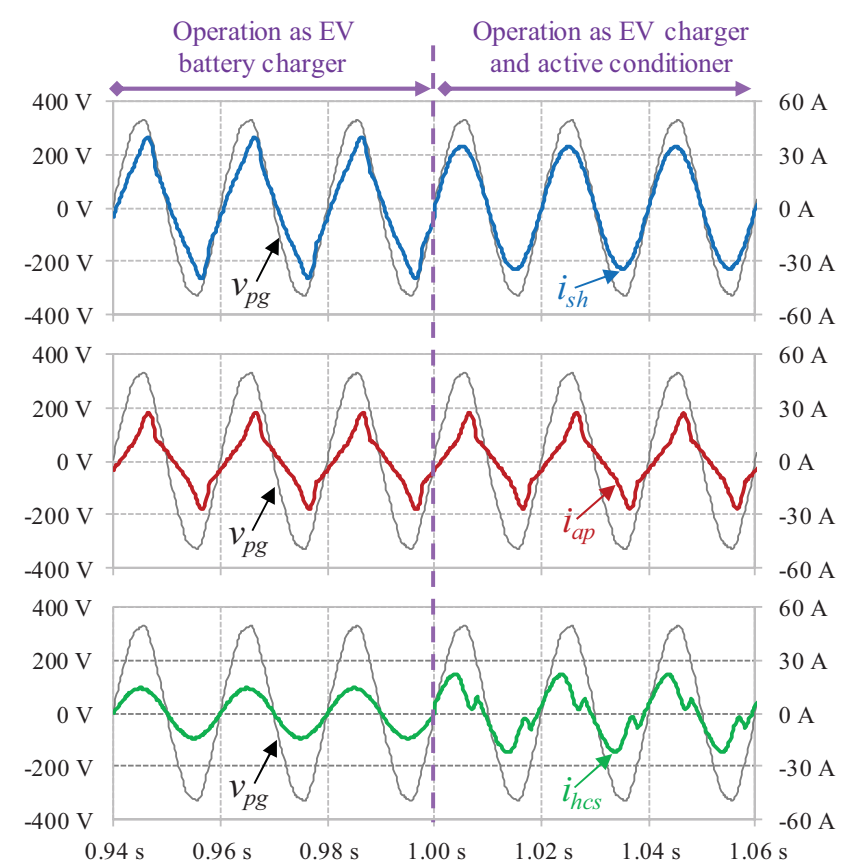

Fig. 5. EV-HCS operation during EV charging and discharging, with compensation of reactive power caused by the nonlinear electrical appliances, showing the waveforms of the grid voltage $\left(v_{p g}\right), \mathrm{SH}$ current $\left(i_{s h}\right)$, electrical appliances current $\left(i_{a p}\right)$, and EV-HCS current $\left(i_{h c s}\right)$.

$\left(P_{A P}, Q_{A P}\right)$, and in the EV-HCS $\left(P_{H C S}, Q_{H C S}, P_{E V}\right)$. This result was attained to show the EV-HCS operation, mainly producing reactive power to the grid, i.e., providing power quality functionalities to the SG. As shown, besides producing reactive power for the $\mathrm{SG}$, it also operates as active conditioner for the $\mathrm{SH}$ (compensating harmonics and reactive power) and charges the EV battery (G2V mode). This result proves the main features and advantages of the EV-HCS for SHs and SGs.

\section{CONCLUSIONS}

An innovative off-board electric vehicle home charging station (EV-HCS) is proposed. As demonstrated along the paper, the EV-HCS represents a strategic equipment, enhancing the operation of smart homes (SHs) and contributing to their dissemination in smart grids. Besides the classical EV battery charging $(\mathrm{G} 2 \mathrm{~V})$ and discharging (V2G) modes, the EV-HCS can also operate with flexible operating power and as an active power conditioner in the SH or smart grid perspective. The validation was performed mainly considering the operation during the EV charging and discharging with compensation of current harmonics and reactive power caused by nonlinear electrical appliances, as well as operation as a function of the power of the other appliances in the $\mathrm{SH}$ creating a power management stratagem. For a $\mathrm{SH}$ scenario, a traditional EV was considered in terms of battery charging requirements (battery with a nominal stored energy of $24 \mathrm{kWh}$ and a charger with a nominal power of $3.5 \mathrm{~kW}$ ), as well as linear and nonlinear electrical appliances in transient and steady-state, validating the control algorithm and the contributions addressed by the EV-HCS.

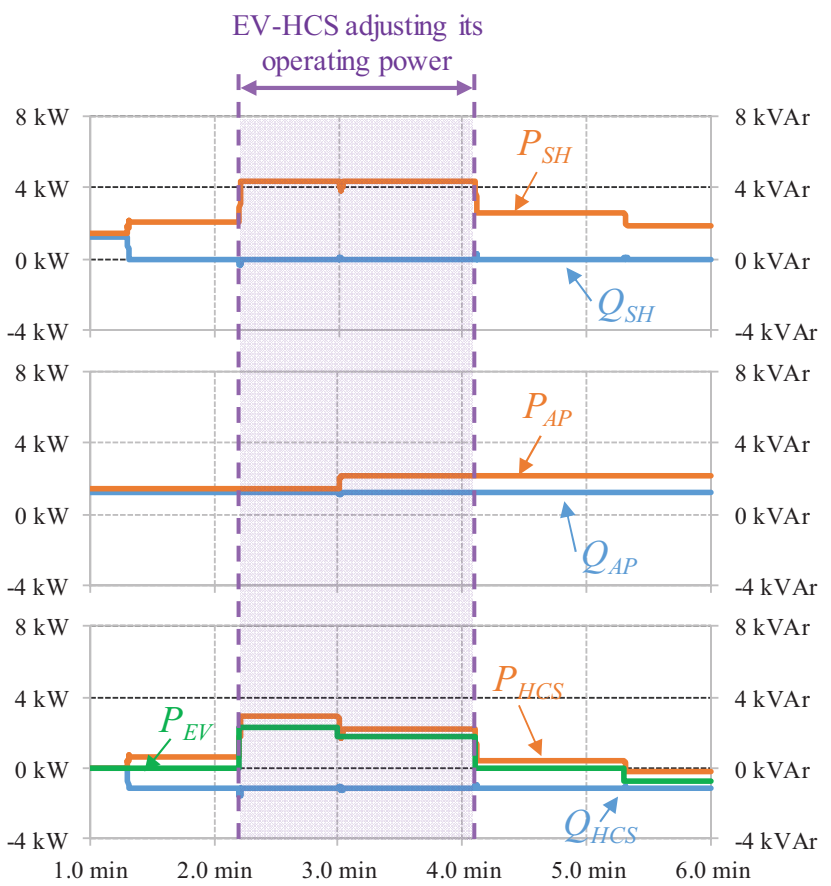

Fig. 6. EV-HCS adjusting its operating power as a function of the operating power of the other electrical appliances in the home, allowing to establish a power management strategy, showing the active and reactive powers in the: $\mathrm{SH}\left(P_{S H}, Q_{S H}\right)$; Electrical appliances $\left(P_{A P}, Q_{A P}\right)$; EV-HCS $\left(P_{H C S}, Q_{H C S}, P_{E V}\right)$.

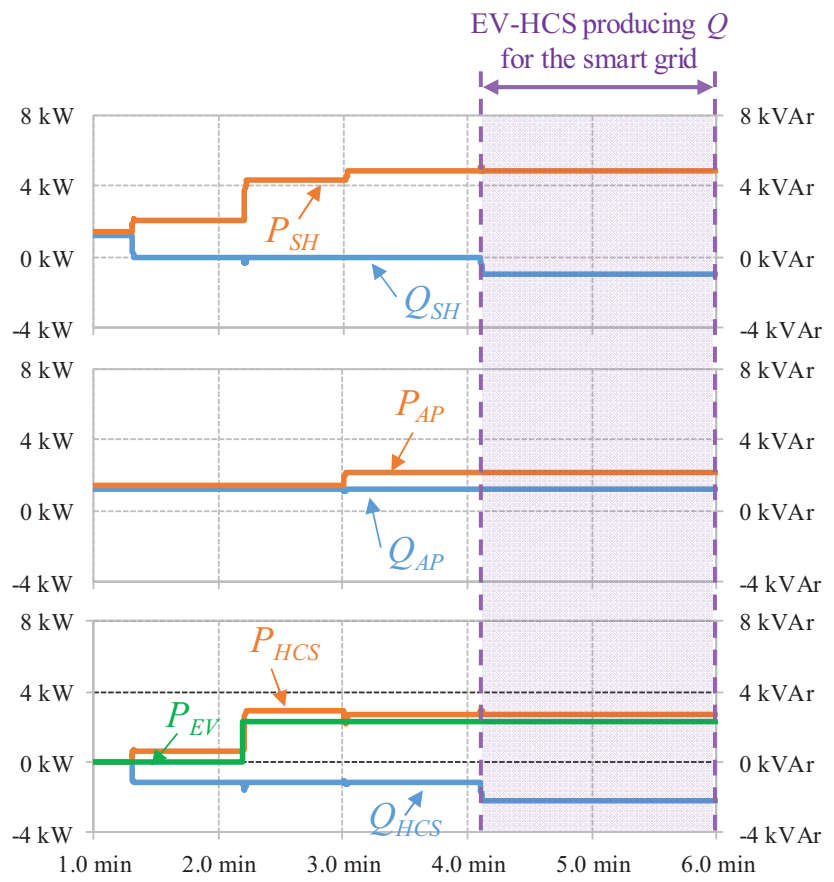

Fig. 7. EV-HCS providing power quality functionalities to the smart grid, besides the operation in $\mathrm{G} 2 \mathrm{~V}$ mode and the operation as active power conditioner for a $\mathrm{SH}$, showing the active power and the reactive power in the: SH $\left(P_{S H}, Q_{S H}\right)$; Electrical appliances $\left(P_{A P}, Q_{A P}\right)$; and EV-HCS $\left(P_{H C S}, Q_{H C S}\right.$, $\left.P_{E V}\right)$.

\section{ACKNOWLEDGMENT}

This work has been supported by COMPETE: POCI-010145-FEDER-007043 and FCT - Fundação para a Ciência e Tecnologia within the Project Scope: UID/CEC/00319/2013. 
This work is financed by the ERDF - European Regional Development Fund through the Operational Programme for Competitiveness and Internationalisation - COMPETE 2020 Programme, and by National Funds through the Portuguese funding agency, FCT - Fundação para a Ciência e a Tecnologia, within project SAICTPAC/0004/2015 - POCI 01-0145-FEDER-016434. Mr. Tiago Sousa is supported by the doctoral scholarship SFRH/BD/134353/2017 granted by the Portuguese FCT agency.

\section{REFERENCES}

[1] Deepak S. Gautam, Fariborz Musavi, Murray Edington, Wilson Eberle, William G. Dunford, "An Automotive Onboard 3.3-kW Battery Charger for PHEV Application," IEEE Trans. Veh. Technol., vol.61, no.8, pp.3466-3474, Oct. 2012.

[2] C. C. Chan, Alain Bouscayrol, Keyu Chen, "Electric, Hybrid, and FuelCell Vehicles: Architectures and Modeling," IEEE Trans. Veh. Technol., vol.59, no.2, pp.589-598, Feb. 2010

[3] João A. Peças Lopes, Filipe Soares, Pedro M. Rocha Almeida, "Integration of Electric Vehicles in the Electric Power Systems," Proc. IEEE, vol.99, no.1, pp.168-183, Jan. 2011.

[4] Peter Richardson, Damian Flynn, Andrew Keane, "Optimal Charging of Electric Vehicles in Low-Voltage Distribution Systems," IEEE Trans. Power Syst., vol.27, no.1, pp.268-279, Feb. 2012.

[5] Rong-Ceng Leou, "Optimal Charging/Discharging Control for Electric Vehicles Considering Power System Constraints and Operation Costs," IEEE Trans. Power Syst., vol.31, no.3, pp.1854-1860, May 2016.

[6] João C. Ferreira, Vitor Monteiro, João L. Afonso, "Electric Vehicle Assistant Based on Driver Profile," Int. J. Electric and Hybrid Vehicles, vol.6, no.4, pp.335-349, 2014.

[7] Vítor Monteiro, Andrés A. Nogueiras Meléndez, Carlos Couto, João L. Afonso, "Model Predictive Current Control of a Proposed SingleSwitch Three-Level Active Rectifier Applied to EV Battery Chargers," IEEE IECON Industrial Electronics Conference, Florence Italy, pp.1365-1370, Oct. 2016

[8] An Luo, Qianming Xu, Fujun Ma, Yandong Chen, "Overview of Power Quality Analysis and Control Technology for the Smart Grid," SPRINGER Journal of Modern Power Systems and Clean Energy, vol.4, no.1, pp.1-9, Jan. 2016

[9] João C. Ferreira, Vitor Monteiro, João L. Afonso, "Vehicle-to-Anything Application (V2Anything App) for Electric Vehicles," IEEE Trans. Ind. Informat., vol.10, no.3, pp.1927-1937, Aug. 2014.

[10] C. Gouveia, D. Rua, F. Ribeiro, L. Miranda, J. M. Rodrigues, C. L. Moreira, J. A. Peças Lopes, "Experimental Validation of Smart Distribution Grids: Development of a Microgrid and Electric Mobility Laboratory," ELSEVIER Electrical Power and Energy Systems, vol.78, pp.765-775, June 2016

[11] Matthias D. Galus, Marina Gonzalez Vaya, Thilo Krause, Goran Andersson, "The Role of Electric Vehicles in Smart Grids," John Wiley and Sons, WIREs Energy Environ, vol.2, pp.384-400, Aug. 2013.

[12] Yutaka Ota, Haruhito Taniguchi, Tatsuhito Nakajima, Kithsiri M. Liyanage, Jumpei Baba, Akihiko Yokoyama, "Autonomous Distributed V2G (Vehicle-to-Grid) Satisfying Scheduled Charging," IEEE Trans. Smart Grids, vol.3, no.1, pp.559-564, Mar. 2012.

[13] Murat Yilmaz, Philip T. Krein, "Review of the Impact of Vehicle-toGrid Technologies on Distribution Systems and Utility Interfaces," IEEE Trans. Power Electron., vol.28, no.12, pp.5673-5689, Dec. 2013.

[14] Rong Yu, Weifeng Zhong, Shengli Xie, Chau Yuen, Stein Gjessing, Yan Zhang, "Balancing Power Demand through EV Mobility in Vehicle-to-Grid Mobile Energy Networks," IEEE Trans. Ind. Informat., vol.12, no.1, pp.79-90, Feb. 2016

[15] Vítor Monteiro, João C. Ferreira, João L. Afonso, "Operation Modes of Battery Chargers for Electric Vehicles in the Future Smart Grids," in Technological Innovation for Collective Awareness Systems, 1st ed. Luis M. Camarinha-Matos, Luis M. Barreto, Nuno S. Mendonça, Ed. Springer, 2014, Chapter 44, pp.401-408.
[16] Vítor Monteiro, João C. Ferreira, Andrés A. Nogueiras Meléndez, João L. Afonso, "Electric Vehicles On-Board Battery Charger for the Future Smart Grids," in Technological Innovation for the Internet of Things, 1st ed., Luis M. Camarinha-Matos, Slavisa Tomic, Paula Graça, Ed. Springer, 2013, Chapter 38, pp.351-358.

[17] David P. Tuttle, Ross Baldick, "The Evolution of Plug-In Electric Vehicle-Grid Interactions," IEEE Trans. Smart Grid, vol.3, no.1, pp.500-505, Mar. 2012

[18] Vítor Monteiro, Bruno Exposto, João C. Ferreira, João L. Afonso, "Improved Vehicle-to-Home (iV2H) Operation Mode: Experimental Analysis of the Electric Vehicle as Off-Line UPS," IEEE Transactions on Smart Grid, vol.8, no.6, pp.2702-2711, Nov. 2017.

[19] Mingrui Zhang, Jie Chen, "The Energy Management and Optimized Operation of Electric Vehicles Based on Microgrid," IEEE Trans. Power Del., vol.29, no.3, pp.1427-1435, June 2014.

[20] Jorge E. Hernandez, Frank Kreikebaum, Deepak Divan, "Flexible Electric Vehicle (EV) Charging to Meet Renewable Portfolio Standard (RPS) Mandates and Minimize Green House Gas Emissions," IEEE ECCE Energy Conversion Congress and Exposition, Atlanta USA, pp.4270-4277, Sept. 2010.

[21] Mosaddek Hossain Kamal Tushar, AdelW. Zeineddine, Chadi Assi, "Demand-Side Management by Regulating Charging and Discharging of the EV, ESS, and Utilizing Renewable Energy," IEEE Trans. Ind. Informat., vol.14, no.1, pp.117-126, Jan. 2018.

[22] Ahmed Yousuf Saber, Ganesh Kumar Venayagamoorthy, "Plug-in Vehicles and Renewable Energy Sources for Cost and Emission Reductions,"IEEE Trans. Ind. Electron., vol.58, no.4, pp.1229-1238, Apr. 2011.

[23] Vehbi C. Gungor, Dilan Sahin, Taskin Kocak, Salih Ergut, Concettina Buccella, Carlo Cecati, Gerhard P. Hancke, "Smart Grid and Smart Homes - Key Players and Pilot Projects," IEEE Ind. Electron. Mag., vol.6, pp.18-34, Dec. 2012.

[24] Chunhua Liu, K. T. Chau, Diyun Wu, Shuang Gao, "Opportunities and Challenges of Vehicle-to-Home, Vehicle-to-Vehicle, and Vehicle-toGrid Technologies," Proc. IEEE, vol.101, no.11, pp.2409-2427, Nov. 2013.

[25] Chenrui Jin, Jian Tang, Prasanta Ghosh, "Optimizing Electric Vehicle Charging: A Customer's Perspective," IEEE Trans. Veh. Technol., vol.62, no.7, pp.2919-2927, Sept. 2013.

[26] Vitor Monteiro, João C. Ferreira, Andres A. Nogueiras Melendez, Carlos Couto, João L. Afonso, "Experimental Validation of a Novel Architecture Based on a Dual-Stage Converter for Off-Board Fast Battery Chargers of Electric Vehicles," IEEE Trans. Veh. Tech., vol.67, no.2, pp.1000-1011, Feb. 2018

[27] Vítor Monteiro, João C. Ferreira, Delfim Pedrosa, João L. Afonso, "Comprehensive Analysis and Comparison of Digital Current Control Techniques for Active Rectifiers," CONTROLO Portuguese Conference on Automatic Control, Guimarães - Portugal, pp.655-666, Sept. 2016

[28] Vítor Monteiro, João Paulo Carmo, J. G. Pinto, João L. Afonso, “A Flexible Infrastructure for Dynamic Power Control of Electric Vehicle Battery Chargers," IEEE Trans. Veh. Technol., vol.65, no.6, pp.45354547, June 2016

[29] Vítor Monteiro, J. G. Pinto, João L. Afonso, "Operation Modes for the Electric Vehicle in Smart Grids and Smart Homes: Present and Proposed Modes," IEEE Trans. Veh. Tech., vol.65, no.3, pp.1007-1020, Mar. 2016.

[30] Márcio C. B. P. Rodrigues, Igor D. N. Souza, André A. Ferreira, Pedro G. Barbosa, Henrique A. C. Braga, "Simultaneous Active Power Filter and G2V (or V2G) Operation of EV On-Board Power Electronics," IEEE IECON Industrial Electronics Conference, pp.4684-4689, Vienna Austria, Nov. 2013.

[31] Mithat C. Kisacikoglu, Burak Ozpineci, LeonM. Tolbert, "EV/PHEV Bidirectional Charger Assessment for V2G Reactive Power Operation," IEEE Trans. Power Electron., vol.28, no.12, pp.5717-5727, Dec. 2013. 